\title{
Influence of Different Injector Structures on Tip Wetting by Visualization Method
}

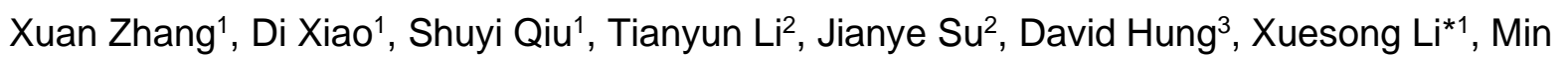 \\ $\mathrm{Xu}^{1}$ \\ ${ }^{1}$ School of Mechanical Engineering, Shanghai Jiao Tong University, 800 Dongchuan Road, \\ Shanghai,China 200240 \\ 2United Automotive Electronic Systems Co., Ltd.No. 555 Rong Qiao Road, Pudong New \\ Area, Shanghai, China 201206 \\ ${ }^{3}$ University of Michigan-Shanghai Jiao Tong University Joint Institute, Shanghai Jiao Tong \\ University,800 Dongchuan Road, Shanghai, China 200240 \\ ${ }^{*}$ Corresponding author email: xuesonl@sjtu.edu.cn
}

\begin{abstract}
The fuel film deposited on the injector tip is considered to have an important influence on the particulate emission of gasoline direct injection (GDI) engines. Although attempts have been made to decrease the tip wetting by optimizing the injector geometry structure, a clear connection has only been found between some injector design parameters and tip wetting. In addition, since the fuel film on the injector tip is very thin, it is difficult to accurately obtain the information of it with conventional measurement methods. To overcome the difficulties and improve the understanding of related tip-wetting mechanisms, tip wettings of different injectors were investigated by laser-induced fluorescence (LIF) method, with gasoline chosen as the working fluid, which could be excited by $266 \mathrm{~nm}$ pulse laser. Then the distribution and evolution characteristics of the tip film could be obtained by post-processing. In the present paper, the influence of the injector structure on tip wetting was analyzed and evaluated quantitatively.
\end{abstract}

Keywords: Direct gasoline injection; Tip wetting; Laser-induced Fluorescence (LIF); Miescattering imaging; Injector structure

Subject area: Liquid drops and Interfaces 


\section{Introduction}

Reducing particulate emissions from gasoline direct injection (GDI) engines has gradually become a hot topic due to increasingly stringent emission regulations worldwide. The fuel film deposited on the injector tip has been determined to be a major source of particulate emissions in GDI engines [1][2]. It will form a fuel-rich zone during the combustion process that leads to insufficient combustion, which in turn produces injector deposits and more particulate emissions [3][4].

In recent years, there are some studies that have shown that the geometry of the injector has a certain influence on the particulate emission of the injector. Dageforde et al. found that a smaller pre-hole diameter would cause qualitatively lower tip wetting [5]. Similarly, Oh et al. reported that nozzle tip wetting could be reduced effectively by decreasing counterbore surface area [6]. In contrast, Huang et al. observed that tip wetting slightly increases firstly and then decreases sharply along with the increase of counterbore diameter, and attributed it to both the needle bouncing and the change of hole configuration [7]. In order to clarify the specific relationship between the injector structure and tip wetting, some research was accomplished, and laser-induced fluorescence (LIF) was adopted to record the fuel film on the tip. Then the distribution and evolution characteristics of the film were obtained by postprocessing. After the data was processed, the possible internal mechanism will be quantitatively analyzed from both the area and strength of the fuel film. We hope this research may help to reduce tip wetting by improving the injector structure.

\section{Material and Methods}

The injector selected in this study includes three types of 2-hole nozzles with different structures. The angle of the tapered hole is positive, $0^{\circ}$, and negative, as shown in Fig. 1 . The other structural parameters of each injector are identical.
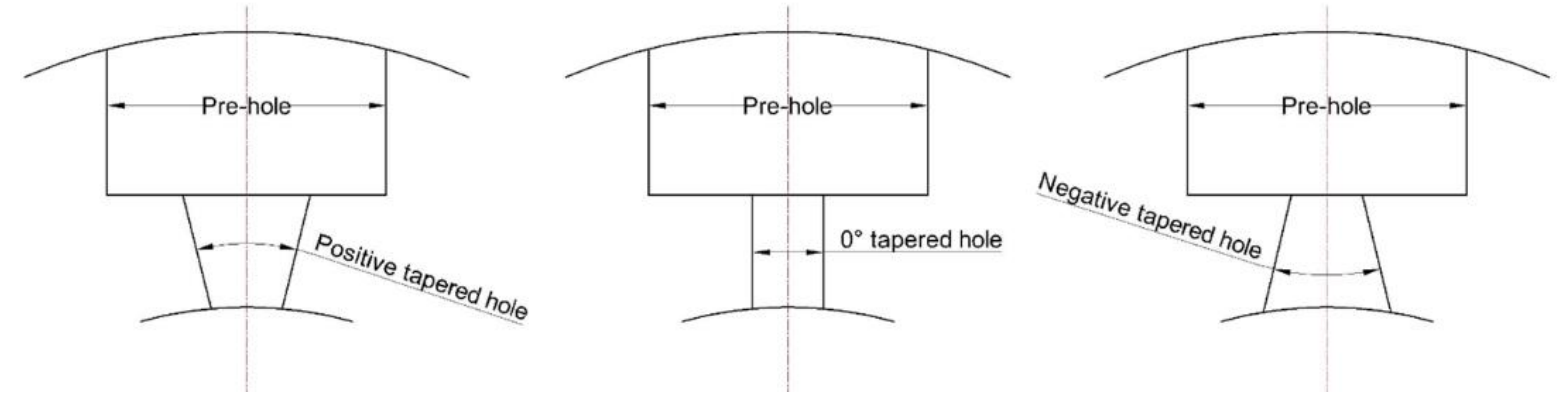

Figure 1. Schematic of different nozzle structures

In order to study the fuel film distribution of different tapered angle injectors, we tested in different working conditions. The specific information is as follows, the temperature of the fuel is $25^{\circ} \mathrm{C}, 90^{\circ} \mathrm{C}, 90^{\circ} \mathrm{C}$, and the ambient pressure is $1.0 \mathrm{bar}, 0.4 \mathrm{bar}, 1.8 \mathrm{bar}$, respectively. The injection pulse width of the injector is $1.5 \mathrm{~ms}, 1.5 \mathrm{~ms}, 3.0 \mathrm{~ms}$, and the injection pressure is 35 $\mathrm{MPa}$. In addition, we tested the fuel film distribution at different timing, which are $5.0 \mathrm{~ms}$, $10.0 \mathrm{~ms}, 15.0 \mathrm{~ms}, 20.0 \mathrm{~ms}, 50.0 \mathrm{~ms}$ after start of injection (ASOI), to observe the evolvement of the fuel film on the tip. Moreover, 15 shots were made under each timing and condition. Incidentally, the test fuel is gasoline. Table 1 shows the test conditions investigated in this study. 
Table 1 - Test conditions

\begin{tabular}{c|ccccc}
\hline NO. & Fuel Pressure(Pf/MPa) & Fuel Temperature $\left(\mathrm{Tf} /{ }^{\circ} \mathrm{C}\right)$ & Ambient Pressure(Pa/bar) & Injector Pulse Width(Ti/ms) & Pa/Ps \\
\hline 1 & 35 & 25 & 1.0 & 1.5 & 16.45 \\
2 & 35 & 90 & 0.4 & 1.5 & 0.51 \\
3 & 35 & 90 & 1.8 & 3.0 & 2.29
\end{tabular}

As an elastic scattering technique, laser-induced fluorescence has a notably higher sensitivity than many other laser spectroscopy methods. Furthermore, it can better capture the information of the fuel film as a 2D optical diagnostics method. In this experiment, A lowspeed laser with $266 \mathrm{~nm}$ wavelength and $10 \mathrm{HZ}$ frequency is used to induce gasoline to emit a broad spectrum of light (320nm-470nm). Since the excited light is very weak, an image intensifier is used to enhance it. After obtaining the results, a quantitative analysis of the film was carried out in term of area and strength (the thicker the film corresponds to the higher the pixel value) statistically. Another feature of this experiment is that during the test, nitrogen injection and vacuum suction were adopted simultaneously to achieve a dynamic balance of pressure in the chamber so that the spray of each injection will not affect the next injection to the greatest extent.

During the test process of a single working condition, since some fuel film will remain on the tip after each injection, a background photo will be taken first. Then we subtract the background photos and the fuel film distribution photos to obtain accurate characteristics of the fuel film. In addition, after each test condition, the tip of the injector will be wiped with alcohol to ensure the accuracy of the experiment. The schematic of the experiments is shown in Fig. 2.

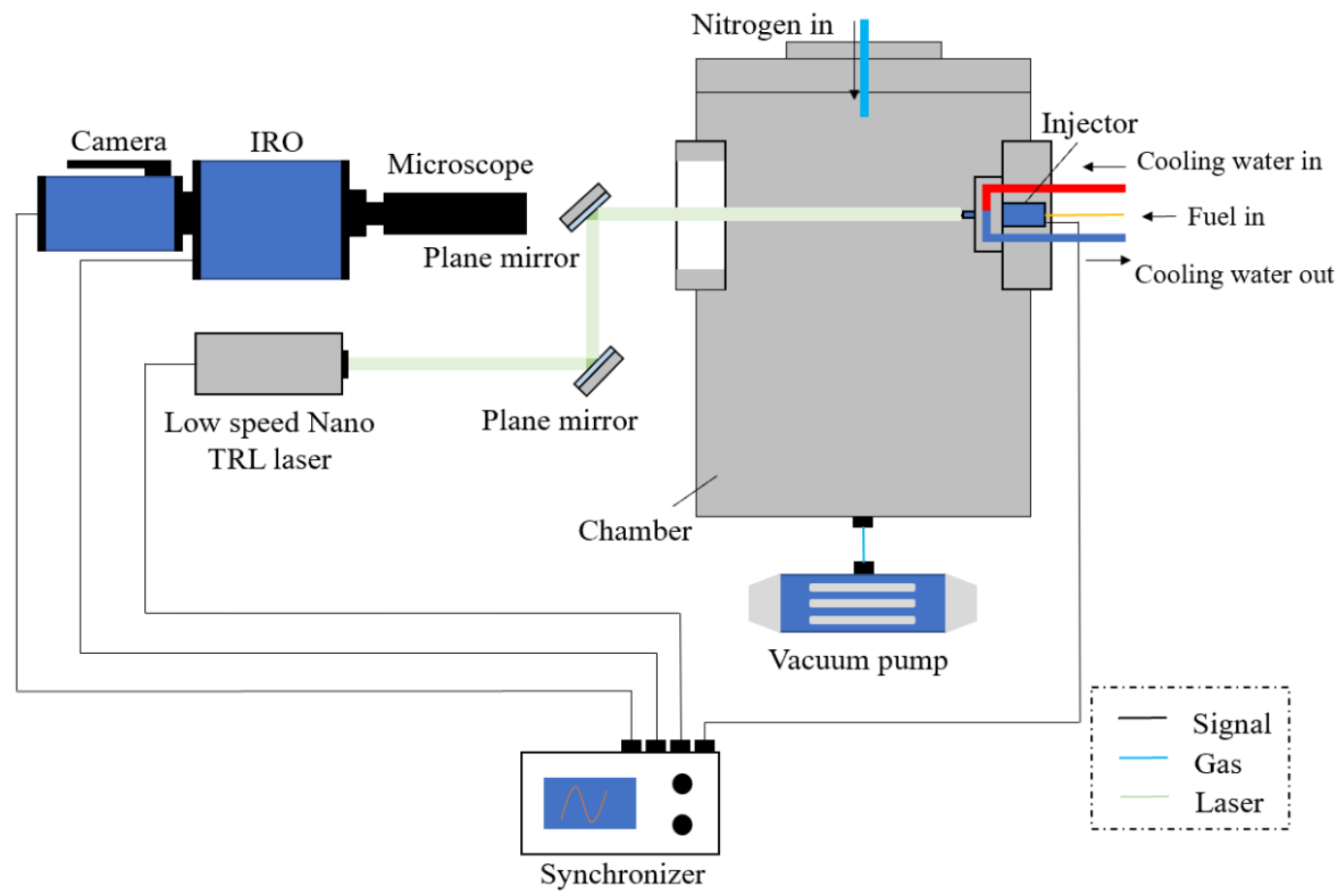

Figure 2. Experimental device system 


\section{Results and Discussion}

In this section, we show the results of the fuel film distribution of different tapered angle injectors under the same working conditions firstly. In order to understand the influence of the tapered angle on the experimental results better, we tested the spatial film distribution at different timings (ASOI). As mentioned earlier, before obtaining the fuel film distribution, we will take a background photo firstly and then subtract it to get more accurate experimental results. At the same time, in the process of data processing, we cut the fluorescence of the nozzle hole to eliminate the influence of the residual fuel in the step hole. With these postprocessing methods, we exhibit representative tip film measurement data under Condition 13 in Fig. 3-5, respectively. The fluorescence signal shown was transient tip fuel film distribution demonstrating representative tip wetting characteristics. As discussed, Condition 1 was subcooled injections, Condition 2 flash boiling injections with low ambient pressure ( 0.4 bar), and Condition 3 high temperature injections with high ambient pressure (1.8 bar). As can be seen in Fig. 3 (sub-cooled conditions), the tip wetting films show similar film characteristics as a function of ASOI. In these conditions, the initial tip wetting film thickness (represented by fluorescence intensity) was not significantly large. As time elapsed, the tip film spread and extended the film size. Considering the evaporation of the tip film, it is suspected that fuel trapped in the step hole escaped after the fuel injection. Nevertheless, the film characteristics did not differ notably with different nozzle hole designs.

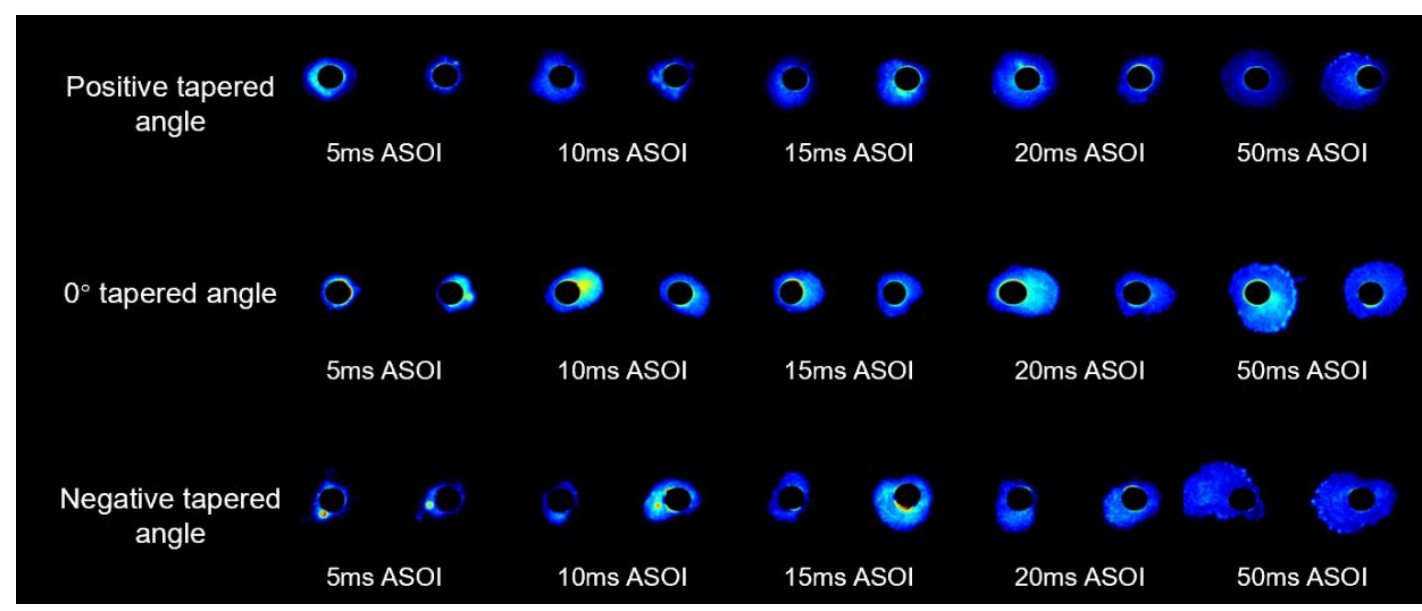

Figure 3. Transient experimental results under Test Condition 1.

Figure 4 depicts the tip wetting phenomena under a higher fuel temperature and low ambient pressure. From the definition of superheat degree, this condition yielded the strongest flash boiling characteristics among the three conditions. In previous studies, it was held that flash boiling would usually yield a worsen tip wetting performance. In our study, part of the results shown in Fig. 4 is in agreement with the existing literature, while the rest of the results is not. As shown, with $0^{\circ}$ tapered holes and negative tapered holes, the tip film both increases in size and fluorescence intensity, reflecting a worsen tip wetting consequence. These results are believed to be caused by flash boiling air entrainment and plume expansion under low ambient pressure. However, with positive tapered holes, the tip film was somehow comparable with the results shown in Fig. 3 (sub-cooled conditions). The initial tip film mass deposited was notably low even under harsh flash boiling conditions. Furthermore, the film lost fluorescence intensity as time progressed, indicating the evaporation effect was stronger than the mass transport effect from the step hole to the tip surface. 
At present, it is hard to establish the exact mechanism why positive tapered holes yield less tip fuel deposition (and this observation is repeatable over 15 shots). There are two possible explanations for this observation: 1 . The exit resistance with positive tapered holes is smaller than the rest two setups. Therefore, it is easier for the dripping fuel to escape the injector hole into the ambient, even when larger droplets/ ligaments will be created during this process; 2 . The positive tapered holes can serve as a diverging nozzle for the flash boiling jets. It is held that for flash boiling atomization, choking could be reached if the working fluid is accelerated to the speed of sound. With a diverging nozzle, it is possible to accelerate the flow into a supersonic flow, thus overcome the choking issue and change the tip deposition features. More experiments will be conducted in our future work to explore the tip wetting mechanisms under flash boiling conditions.

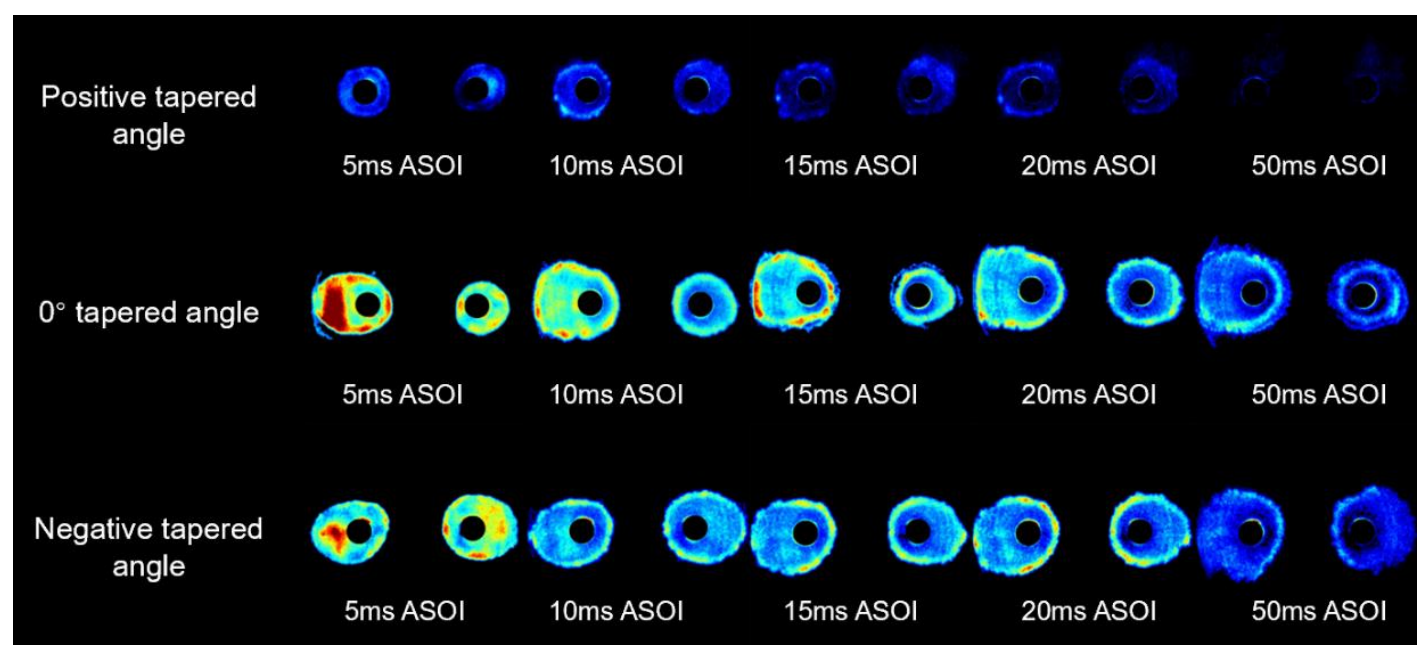

Figure 4. Transient experimental results under Test Condition 2.

Figure 5 depicts the tip wetting results under high ambient pressure with a high fuel temperature. As the ambient pressure increased, the flash boiling effects were eliminated (especially the plume expansion tendency). Under this condition, the tip wetting phenomena for all three nozzle hole designs are suppressed. Furthermore, the evaporation of the tip film was enhanced due to a high temperature. Therefore, the area and the thickness of tip film with all three nozzle designs dropped after a certain ASOI and became nearly negligible around $50 \mathrm{~ms}$ ASOI. The results indicate that flash boiling atomization does necessarily lead to worsened tip wetting performance in fuel injection applications.

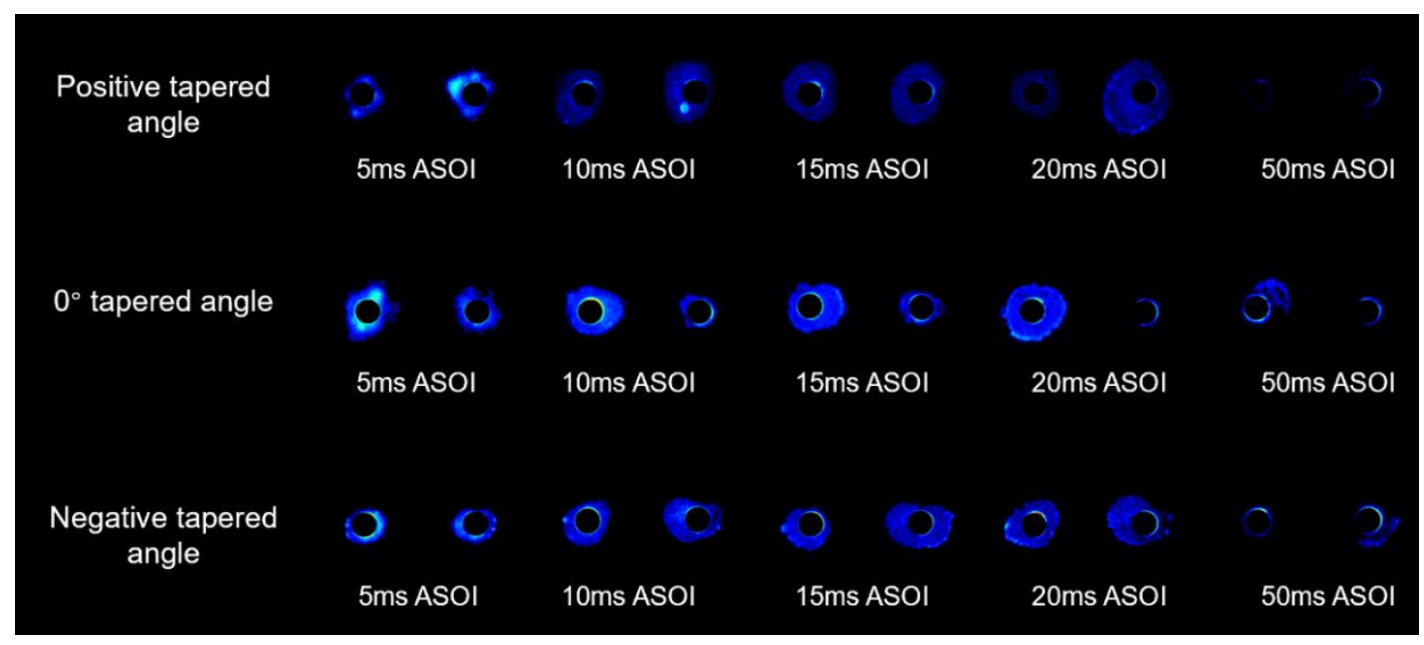

Figure 5. Transient experimental results under Test Condition 3. 
Figure 6 and Fig. 7 show the film area and integrated film fluorescence at different ASOls under various conditions. The results from 15 tests were analyzed, and the mean + std of the results are plotted in the figures. The trends in Fig. 6 and Fig. 7 generally match our discussions in the previous section. In the aspect of film area (obtained by counting pixels), the film area with a fuel temperature of $25^{\circ} \mathrm{C}$ witnessed a steady increase in film area, while the film area with a fuel temperature of $90^{\circ} \mathrm{C}$ dropped after $15 \mathrm{~ms}$ ASOI for positive tapered holes under Condition 2 and all designed under Condition 3, which is directly associated with enhanced evaporation performance. Under Condition 3, the end film area was even smaller than that under sub-cooled conditions (although the engine spark timing will limit the end ASOI timing and corresponding film area). Furthermore, the tip film with positive tapered holes exhibited a stronger evaporation trend (a greater declining slope), which should be expected with low ambient pressure. The results reflect that flash boiling tip wetting can be suppressed by modifying the nozzle design (at least for this two-hole nozzle, tip wetting due to collapse needs to be investigated separately). The film mass shown in Fig. 7 demonstrates similar conclusions that a high fuel temperature would enhance film evaporation; therefore, Condition 3 produces the smallest film mass overall. Without nozzle modifications, Condition 2 generated remarkably more fuel film deposited onto the injector tip.

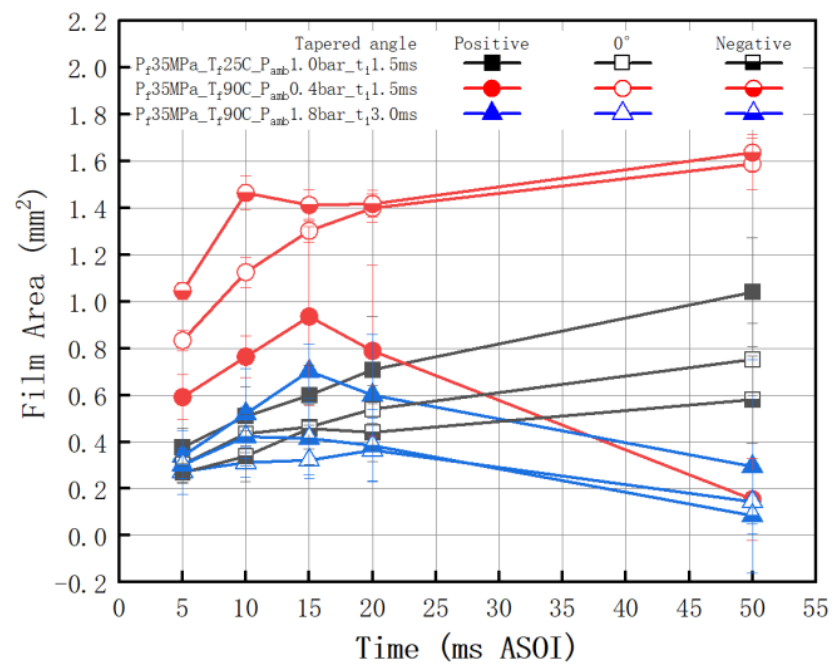

Figure 6. Fuel film area as a function of time (AOSI).

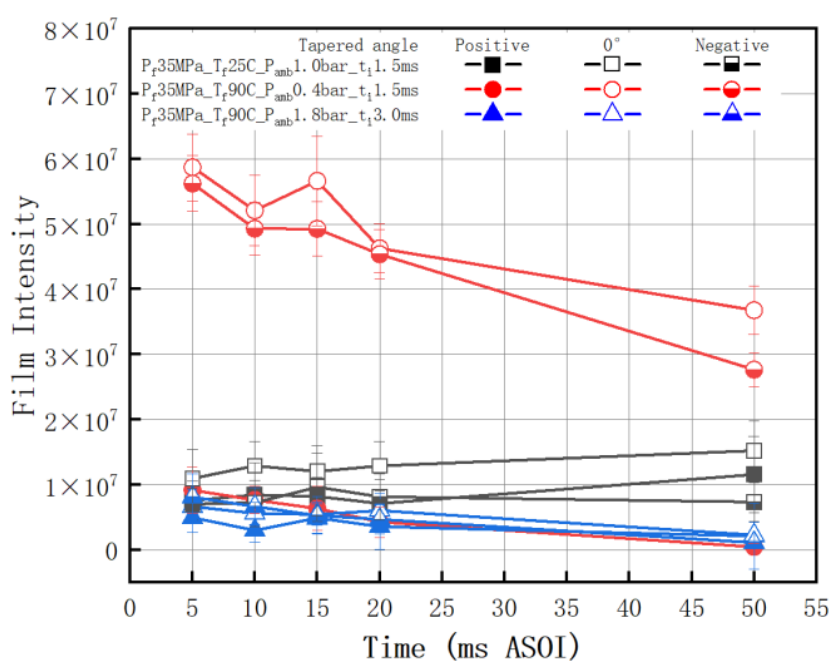

Figure 7. Fuel film integrated intensity (representing film mass) as a function of time (AOSI). 


\section{Conclusions}

In this study, we investigated the tip wetting with two-hole injectors of different tapered holes under different thermal boundary conditions. The conclusions of this investigation are listed as follows:

1. With a high fuel temperature and low ambient pressure, the tapered angle of the injector has a great influence on its tip wetting characteristics. It was found that positive tapered nozzles can suppress undesirable tip wetting phenomenon cause by flash boiling. Possible explanations were given, while the exact mechanism for this observation needs to be further examined.

2. The elevation of ambient pressure can also suppress flash-boiling-induced tip wettings since the plume expansion was limited. Furthermore, a higher fuel temperature would promote film evaporation after the fuel injection, thus the film area and mass would reach a peak value under this condition, then drop as the evaporation effect dominates.

\section{Acknowledgments}

The authors would like to acknowledge the financial support and technical contribution to this project from United Automotive Electronic Systems Co., Ltd. This research was also sponsored by the National Natural Science Foundation of China (NSFC) under Grants No. E52006140 and No. E51876126. The study was carried out at the National Engineering Laboratory for Automotive Electronic Control Technology of Shanghai Jiao Tong University.

\section{References}

[1] OudeNijeweme D, Freeland P, Behringer M, et al. Developing low gasoline particulate emission engines through improved fuel delivery[R]. SAE Technical Paper, 2014.

[2] Berndorfer A, Breuer S, Piock W, et al. Diffusion combustion phenomena in GDI engines caused by injection process[R]. SAE Technical Paper, 2013.

[3] Imoehl W, Gestri L, Maragliulo M, et al. A DOE approach to engine deposit testing used to optimize the design of a gasoline direct injector seat and orifice[J]. SAE International Journal of Fuels and Lubricants, 2012, 5(3): 1078-1095.

[4] Imaoka Y, Hashizume $Y$, Inoue $T$, et al. A Study of Particulate Emission Formation Mechanism from Injector Tip in Direct-Injection Gasoline Engines[J]. SAE International Journal of Advances and Current Practices in Mobility, 2019, 2(2019-01-2244): 376-384.

[5] Dageförde H, Kiefer A, Samenfink W, et al. Requirements for spray and tip design of a multi-hole injector for DISI engines[J]. Proceedings of ICLASS, Tainan, 2015, 3.

[6] Oh H, Lee J H, Han S, et al. Effect of injector nozzle hole geometry on particulate emissions in a downsized direct injection gasoline engine[R]. SAE Technical Paper, 2017.

[7] Huang W, Moon S, Wang J, et al. Nozzle tip wetting in gasoline direct injection injector and its link with nozzle internal flow[J]. International Journal of Engine Research, 2020, 21 (2): 340351. 